\title{
Valores na escola
}

\author{
Maria SuzanaDe Stefano Menin \\ Universidade do Estado de São Paulo-Presidente Prudente
}

\section{Resumo}

Neste texto pretende-se discorrer sobre valores morais na escola e suas implicações para a formação de professores. Para tanto discutir-se-á, em primeiro lugar, e brevemente, o que são valores morais, ou éticos, e como a escola pode situar-se em relação a eles. Em seguida, serão relatadas algumas observações a respeito de valores de professores e práticas daí decorrentes. São comentados resultados de pesquisa que ilustram a transmissão de valores de forma doutrinal e a educação moral e cívica tal como realizada na ditadura militar, e, por outro lado, a posição relativista e/ou de laissez-faire que certas escolas podem adotar, metodologicamente, sobre a educação em valores. Finalmente, defender-se-á a idéia de que é necessária uma discussão sobre valores pelos diversos membros da escola e uma opção por uma metodologia para ensiná-los, seja os professores, em sua formação inicial e continuada, seja os alunos. A teoria de desenvolvimento moral de Jean Piaget será apresentada como uma referência possível para a educação em valores. Exemplos de situações escolares de conflito de valores entre direção, pais e alunos são discutidas para ilustrar como uma escola pode adotar um procedimento democrático de educação em valores, que se apresenta como um terceiro caminho possível de educação moral nas escolas, além das posições doutrinárias ou relativistas.

\section{Palavras-chave}

Ética na escola - Valores - Educação moral - Valores de professores.

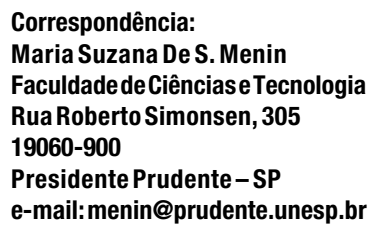




\title{
Values at school
}

\author{
MariaSuzana De Stefano Menin \\ Universidade do Estado de São Paulo - Presidente Prudente
}

Abstract

This text deals with moral values at school and their implications to the formation of teachers. It will therefore discuss briefly and at first what moral or ethical values are, and how the school may position itself with regard to them. Some observations related to teacher's values and the practices engendered by them will then be presented.

Comments are made on the results of a research that illustrates the transmission of values in an indoctrinal manner, and the civic and moral education as carried out during the military dictatorship, and, on the other hand, the relativistic and/or laissez-faire position certain schools can adopt, in methodological terms, with respect to the education of values. Finally, the text will defend the idea that a discussion about values is necessary among the several members of the school, leading to a methodological choice to teach both the teachers, in their continuing education, and the pupils.

Jean Piaget's theory of moral development will be presented as a possible reference to the education of values. Examples of situations of conflict of values at school involving the management, parents and pupils will be discussed to illustrate how a school can adopt a democratic procedure in the education of values, which presents itself as a possible third path in the education of values at school, beyond indoctrinal or relativistic positions.

\section{Keywords}

Ethics at school - Values - Moral education - Teachers.

Correspondence:

Maria Suzana De S. Menin

Faculdade de Ciênciase Tecnologia

Rua Roberto Simonsen, 305

19060-900

Presidente Prudente-SP

E-mail:menin@prudente.unesp.br 
Temos acompanhado as produções de um grupo de pesquisadores espanhóis que têm-se dedicado à educação moral ou em valores na escola (Grem - Grupo de Ricierca en Educación Moral). Antes de nós, e provavelmente nos fornecendo modelos atuais de educação moral, autores como Cabanas (1996), Puig (1998), Buxarrais (1990,1997), Martinez (1994), e Martinez e Puig (1994) chegaram à proposição da ética como tema transversal nas escolas, o que agora aparece em nossos Parâmetros Curriculares Nacionais (1998).

Mas o que é ética, ou moral, e como colocá-las nas escolas? Segundo Cabanas (1996), a questão central da ética é a de responder à pergunta: o que nos obriga a sermos bons? Ou seja, é a ética que nos permite buscar critérios para definirmos o que é ser bom, correto ou moralmente certo e que nos fornece explicações para nosso senso de dever moral. A essa questão - o que me obriga a ser bom -, podem ser dadas respostas diferentes, ancoradas em diversas posições filosóficas ou ideológicas; e é quando a respondemos que encontramos valores morais.

Segundo Cabanas (1996), para algumas posições filosóficas, valores são os critérios últimos de definição de metas ou fins para as ações humanas e não necessitam de explicações maiores além deles mesmos para assim existirem. Ou seja, devemos ser bons porque a bondade é um valor, honestos porque a honestidade é um valor, e assim por diante com outros valores como a solidariedade, a tolerância, a piedade, que têm um caráter natural, universal e obrigatório em nossa existência. Para outras posições, os valores são determinados por culturas particulares e em função de certos momentos históricos, variando, portanto, de acordo com cada sociedade e período de sua existência. As ações humanas seriam, assim, avaliadas de acordo com os costumes locais; algo considerado um dia como correto e justo poderia ser, em outra época, considerado errado ou injusto.
Metodologicamente, podem acontecer, também, posturas opostas sobre como educar em valores. Há posturas doutrinárias, de acordo com as quais acredita-se que um conjunto de valores, considerados fundamentais, devem ser transmitidos prontos a todos, como verdades acabadas; e, por outro lado, há posturas mais relativistas, com as quais a escola eximese de assumir tal educação em valores deixando que isso ocorra de forma assistemática, não-planejada, nos seus mais diversos espaços. Escolas religiosas, por exemplo, adotam uma postura doutrinária quando catequizam seus alunos a respeito de valores como fé, piedade, amor ao próximo, respeito, caridade, tolerância e outros. Certos valores são tomados como postulados, verdadeiros por si próprios e, deles, outros são derivados: a existência de Deus em cada um de nós e o respeito ao próximo como o respeito a ele, por exemplo. Nesses casos, normalmente deixa-se para certos professores especialistas o ensino da moral como matéria à parte, com statuspróprio. Essa posição pode não refletir uma ideologia comum a toda uma escola; pode ocorrer em escolas laicas e estar em certos professores que assumem, para si, a transmissão de valores considerados por eles como essenciais. Numa pesquisa realizada em 1992 (Menin, 1992), com classes de primeiro colegial de uma escola pública, observamos uma professora de Biologia que, antes de suas aulas, passava na lousa provérbios ou pequenos ditados morais a seus alunos e solicitava a estes que os copiassem e os memorizassem pois cairiam como matéria nas suas avaliações. Alguns exemplos das frases colocadas pela professora:

Não deixe que a calúnia o perturbe! Todos nós estamos sujeitos à calúnia. Mas saiba superá-la, vivendo de tal maneira que o caluniador não tenha razão.

Não revide um ataque com outro ataque.

Não se magoe com o caluniador.

Perdoe sempre.

Apenas vive de tal maneira que jamais o 
caluniador tenha razãa (Menin, 1992, p. 496)

... a felicidade não pode estar em nada que esteja fora de vocês. Busque-a dentro de você mesmo; pois a felicidade é Deus e Deus mora dentro de você.

Pense positivamente, nossos pensamentos emitem ondas reais que se irradiam de nosso cérebro... Pensamentos positivos atraem coisas positivas. Pensamentos negativos atraem coisas negativas.

Os homens por amor vão muito além daquilo que a imposição, o dever, a razão, a necessidade conseguem obter deles. (Menin, 1992, p. 498)

Após escrever cada frase, a professora tecia comentários sobre elas e buscava relacioná-las à vida escolar do aluno. Por exemplo, após o última frase citada a professora comentou:

Um aluno que ri da nota E não se valoriza. É preciso ver que você é importante... tenha um ideal de vida. Se você não se valorizar ninguém vai querer ficar com você. Primeiro é se amar, colocar amor em tudo o que você faz: dê valor à escola, dê valor ao que é seu, o seu caderno, por exemplo. Valorize o seu caderno. (Menin, 1992, p. 498)

Esse é um claro exemplo de uma educação em valores realizada de forma explícita, por transmissão de normas prontas, assumida por um professor e por meio da qual se colocam normas morais no mesmo status que matérias científicas para as quais se cobram estudo e obediência.

Tivemos no Brasil, durante a ditadura militar (1969 a 1986), um exemplo de educação moral nas escolas realizada, também, de forma doutrinária. As disciplinas Educação Moral e Cívica ou Estudos dos Problemas Brasileiros eram consideradas matérias específicas e por intermédio delas professores especialis- tas deveriam passar certos valores assumidos como fundamentais. Lepre (2001) relata, em sua dissertação sobre indisciplina e estágios de julgamento moral em crianças de ensino fundamental, como essas disciplinas foram estruturadas pelo decreto-lei de 1969 com a clara finalidade de controlar a "desordem social" vista como causadora dos malefícios da sociedade brasileira. Valores como o nacionalismo, visto como o amor à pátria e aos seus governantes para o alcance do progresso geral, foram colocados como fins de toda a educação. São exemplos de trechos do decreto de 1969:

A Educação Moral e Cívica, apoiando-se nas tradições nacionais, tem como finalidade: a defesa do princípio democrático, através da preservação do espírito religioso, da dignidade da pessoa humana e do amor à liberdade com responsabilidade, sob a inspiração de Deus;

a preservação, o fortalecimento de valores e a projeção de valores espirituais e éticos da nacionalidade;

o fortalecimento da unidade nacional e do sentimento de solidariedade humana;

o culto à Pátria, aos seus símbolos, tradições, instituições e aos grandes vultos de sua história;...

o culto à obediência à lei, da fidelidade ao trabalho, e da integração na comunidade;

(...). ( Lepre, 2001, p. 71-72)

Nesse mesmo decreto estabelecia-se a obrigatoriedade de todas as escolas terem um professor dessas matérias e, caso não houvesse um, o diretor da escola deveria responsabilizar-se por ela. Foi criada, também, uma Comissão Nacional de Moral e Civismo (CNMC), integrada por nove membros escolhidos pelo presidente da República, que tinha como funções básicas: verificar a implantação e manutenção da doutrina de Educação Moral e Cívica nas escolas; colaborar na elaboração do currículo para essa disciplina; influenciar e convo- 
car a cooperação das instituições e órgãos formadores da opinião pública (difusão cultural, jornais, revistas, teatros cinemas, estações de rádio e televisão...) para servir aos objetivos da Educação Moral e Cívica; assessorar o Ministério da Educação na aprovação de livros didáticos, etc.

Ora, todos sabemos dos frutos desse período de educação moral nas escolas feita dessa forma doutrinária por imposição de valores morais acabados, assim como podemos prever as reações dos alunos daquela professora de Biologia que passava ditados morais na lousa: valores impostos por uma autoridade são aceitos por temor enquanto perdurar o controle dessa autoridade e deixam de ser assumidos como valores no momento em que a força do controle é enfraquecida. Todos nós que assistimos às aulas, na época, de Educação Moral e Cívica, sabemos o quanto essa disciplina nos parecia artificial, demagógica e como se tornou alvo de desprezo a ponto do termo Educação Moral se tornar algo pejorativo no Brasil e em outros países que passaram por processos semelhantes.

A educação em valores nas escolas pode, no entanto, se dar de forma oposta à maneira doutrinária. É o laissez-faireem termos de valores: cada professor e seus alunos podem ter posições diferentes sobre o que é correto, bom, justo, ou seja, sobre o que tem valor. Nesse caso, a escola não teria um código moral ou de valores declarado e assumido, e a adoção de valores seria questão individual, pessoal. Predomina o entendimento de que tudo é relativo e de que não há obrigatoriamente uma posição mais correta que outra. Nessas escolas, o corpo de professores pode ser completamente diverso em termos dos valores mais adotados e sua transmissão fica a cargo de cada um, de forma assistemática e acidental. Assim, podem existir, na mesma escola, professores que incentivam a cooperação entre alunos, outros a competição; alguns teriam aversão às mais variadas formas de violência, en- quanto outros seriam tolerantes a certas manifestações violentas ou agressivas dos alunos ou dos próprios professores.

Observações de certas práticas disciplinares nas escolas e das regras que os professores dispõem aos alunos podem revelar uma grande diversidade de valores entre os mesmos e até incompatibilidades. Assim, por exemplo, embora constatemos que nos últimos anos têm-se fortalecido uma posição antiviolência nas escolas, como as campanhas pela paz, de 1998 para cá, observamos, no entanto, na mes-ma época, em cursos para professores de pré-escola, que a violência física entre crianças pode ser admitida como uma forma de realizar justiça. Ainda predomina via senso comum que o revide é uma forma justa de resolver conflitos entre crianças ou que uma criança que apanhou não deve voltar para casa chorando; é a mentalidade do "levou, bateu”. É importante nos perguntar como isso pode ser tolerado e mesmo, às vezes, ensinado nas escolas e, em seguida, exigir-se dos adolescentes que tenham controle sobre sua agressividade.

Uma posição relativista em educação de valores pode permitir, como podemos constatar, um vale-tudo na educação, em que valores e contravalores podem coexistir e nem sempre serem fruto de reflexão ou de sua clara adoção. Podem, numa mesma escola, ser encontrados professores que incentivam a competição entre alunos ancorando-se no fato de que na sociedade atual predomina o "cada um por si" ou o "vence o mais forte", outros defendendo a cooperação e a solidariedade para a construção de uma sociedade melhor, e outros, ainda, completamente indiferentes a essas questões e que consideram a moral como um assunto particular.

Numa pesquisa realizada por Shimizu (1998) em que foram entrevistados quarenta professores das séries iniciais da rede pública numa cidade do interior paulista, constatou-se que eles conheciam muito pouco das teorias psicológicas que poderiam lhes dar uma base para realizar algum tipo de educação moral e 
que utilizavam, na grande maioria, opiniões do senso comum para decidir o que é moral, imoral ou como educar moralmente. Assim, nessa pesquisa, grande parte dos professores afirmou que a moralidade de seus alunos vem de exemplos familiares, de influências religiosas e pouca importância foi dada à própria escola nessa formação: é como se houvesse a crença que, em moral, a família é tudo e a escola, nada.

Vemos que as duas posições extremistas sobre educação em valores têm-nos levado a erros ou são completamente ineficazes como forma de educar moralmente e poderíamos então nos perguntar: existem outras posições?

Autores como Cabanas (1996), Buxarrais (1990,1997) e Martinez (1994) buscam apresentar uma outra posição sobre valores e educação moral ou ética, inspirada, principalmente, nos ensinamentos de Piaget (1977). Esse autor, estudando a construção da moralidade infantil, descobriu que o desenvolvimento das crianças mostra duas tendências basicamente opostas de moral: a "moral do dever", ou heteronomia, e a "moral do bem", ou autonomia, e que a segunda sucederia a primeira em condições normais de desenvolvimento. Na moral heterônoma, uma criança segue as normas fixadas pelas autoridades que a rodeiam (pais, irmãos mais velhos, etc.) e as obedece por temor à perda de afeto ou ao castigo; é uma moral fruto de um tipo de relação social em que predomina o respeito unilateral e que Piaget chamou de coação. As educações doutrinárias fortaleceriam, para Piaget, essa moral heterônoma. Noutro extremo, e como resultado da formação na qual a criança pode se ver cada vez mais livre de autoridades e capaz de construir normas entre iguais, surgiria a moral da autonomia por meio da qual o adolescente decide pelas normas que quer obedecer porque participou de sua construção e verificou os benefícios que aquela norma pode ter para o seu grupo de companheiros. Nesse sentido a norma livremente consentida passa a ser respeitada em função de relações de respeito mútuo entre indivíduos mais iguais entre si e guiadas pelo princípio da reciprocidade a mais ampla possível. Na moral heterônoma todo um conjunto de crenças e ações da criança revela sua posição imitativa e egocêntrica em relação aos outros. As crianças, por exemplo, imitam o uso das regras pelos mais velhos, mas não conseguem regular seus próprios comportamento por elas; acreditam que as regras são sagradas e imutáveis; julgam os outros mais pela conseqüência de seus atos que pelas suas intenções (o que demandaria uma descentração da criança no sentido de colocarse no lugar do outro para compreendê-lo); acreditam que as mentiras piores são as mais aparentes ou que algo é mais errado quanto mais se corre o risco de ser descoberto e punido. Na moral autônoma, ao contrário, o adolescente discute as regras que regem sua vida no grupo e pode reelaborá-las passando a entender as utilidades sociais das regras, e os atos dos outros passam a ser julgados pela intenção; os piores atos são aqueles que mais quebram os laços de solidariedade e confiança entre as pessoas mesmo que pouco aparentes ou não puníveis. Em uma palavra, na moral da autonomia, tal como é vista por Piaget (1977), ser correto, moralmente falando, não depende de quais regras são seguidas, mas dos princípios de sua obediência. Seguindo uma visão kantiana, Piaget vê, na moral heterônoma, a adoção de regras, normas ou de valores morais como guiada por motivos extrínsecos à pessoa: é o medo, o controle de uma autoridade, o receio da perda de afeto que leva à uma obediência situacional. Ao contrário, na moral autônoma o autor vê um indivíduo que reflete sobre a justiça de suas opções morais considerando se poderiam valer para si ou para qualquer pessoa desse mundo; é a reciprocidade levada ao infinito.

$\mathrm{Na}$ visão piagetiana e de autores que nele têm-se inspirado, a educação moral ou educação em valores não poderia jamais se dar 
na forma de imposição de valores, por melhores que estes fossem, nem deixada à livre escolha de cada um. Piaget (1996) argumenta que na moral os meios usados no ensino são tão fundamentais quanto os fins. Se quisermos educar para a autonomia (a adoção consciente e consentida de valores) não é possível obtêla por coação; ou seja, se quisermos formar alunos como pessoas capazes de refletir sobre os valores existentes, capazes de fazer opções por valores que tornem a vida social mais justa e feliz para a maioria das pessoas, capazes de serem críticos em relação aos contra-valores, então é preciso que a escola crie situações em que essas escolhas, reflexões e críticas sejam solicitadas e possiveis de serem realizadas. É como se, em moral, meios e fins fossem iguais: não se ensina cooperação como um valor sem a prática da cooperação, não se ensina justiça, sem a reflexão sobre modos equilibrados de se resolverem conflitos; não se ensina tolerância sem a prática do diálogo.

Assim, numa visão piagetiana, a formação moral de alunos e/ou de professores passa, obrigatoriamente, pelo exercício da construção de valores, regras e normas pelos próprios alunos e/ou professores entre si e nas situações em que sejam possíveis relações de trocas intensas; troca de necessidades, aspirações, pontos de vistas diversos, enfim: quanto maiores e mais diversas forem as possibilidades de trocas entre as pessoas, mais amplo poderá ser o exercício da reciprocidade - pensar no que pode ser válido, ou ter valor, para mim e para qualquer outro.

A posição piagetiana não considera os valores como relativos, pois há uma clara opção pela autonomia moral como melhor, racional e moralmente falando, que a heteronomia. Há, também, uma opção pelos métodos ativos de educação moral, que passam pelas possibilidades de prática de cooperação, solidariedade, justiça, respeito mútuo. Para Piaget $(1977,1996)$, e autores que o têm seguido, e para nossos atuais
Parâmetros Curriculares Nacionais(1998), saber sobre a moral é sinônimo de um saber fazer, um saber viver relações cooperativas e justas; sem isso a moral é puro verbalismo. Onde e como se daria, então, essa formação prática de professores para a moralidade? Dar-se-ia em todos os espaços escolares em que as relações humanas e seus conflitos pudessem aparecer e onde se pudesse refletir sobre as melhores soluções para todos. Como os PCNs agora buscam dispor, a ética torna-se um tema transversal a ser pensado por todos os professores e nos mais variados espaços da escola; do currículo às relações pessoais dentro da escola e às salas de aula. E a formação, seja de professores ou de alunos, tem que acontecer nas próprias práticas e vivências dentro da escola e nunca como matéria à parte.

Vou dar um exemplo de uma situação verídica que aconteceu numa escola pública para discutir o que ali poderia acontecer em termos de educação moral de professores e alunos e o que não aconteceu. Esse exemplo é relatado numa pesquisa piloto, realizada por Klébis (Klébis e Menin, 2000) que transformou um fato real num dilema moral, apresentado a trinta professores de três escolas públicas. 0 dilema foi o seguinte:

Uma determinada escola pública recebeu a denúncia que alguns alunos estariam levando "droga" para ser distribuída dentro da escola. A diretora comunicou o fato à Polícia Militar que determinou a averiguação da denúncia imediatamente. Justamente neste dia, uma $5^{\text {a }}$ série estava em aula vaga no pátio devido à falta de um professor. Eram alunos cuja faixa etária se concentrava entre 10 a 12 anos. Com a chegada da Polícia Militar na escola, a Diretora solicitou à inspetora de alunos que chamasse os meninos para a sala de vídeo, dizendo aos mesmos que eles iriam assistir a uma projeção. Em hipótese alguma os alunos deve-riam saber 
que os policiais estavam na escola. $\mathrm{Na}$ sala de vídeo, os alunos foram submetidos a uma revista pelos policiais, ficando apenas de cuecas. Como se não bastasse, passaram pelo constrangimento de terem que abaixar a cueca, ficando de cócoras (procedimento usado nos presídios para detectar a presença de droga no ânus). A Diretora argumentou, em resposta à revolta dos pais, que sua intenção era a de proteger os alunos contra as drogas que poderiam estar circulando pela escola, bem como descobrir os culpados.

Após o dilema, Klébis pusera aos professores questões como:

Você acha que a Diretora agiu bem chamando os policiais? Justifique.

Ela deveria permitir que os policiais revistassem os meninos? Justifique.

Você acha que este era o papel dos policiais? Justifique.

Tiveram os pais motivos para se revoltarem? Justifique.

Se você fosse aluno desta escola, o que pensaria? (Klébis e Menin, 2000, p. 36)

As autoras da pesquisa analisaram as respostas dos professores em termos de estágios de julgamento moral, segundo Kohlberg (1992), mas não é isso o que gostaríamos de mostrar aqui. 0 que é interessante relatar é que, na primeira questão, dos trinta professores das três escolas, foram a favor da diretora: $27 \%$ da primeira escola, 56\% da segunda e 90\% da terceira escola. Os professores a favor da ação da diretora apontaram que era preciso manter a ordem, proteger os alunos a qualquer custo, e a polícia era o órgão competente para esse tipo de investigação e controle.

Pergunto, como nos fez antes Piaget (1996), se esse método de educação pode formar personalidades autônomas: chamando a polícia à escola, ensinamos às crianças os malefícios da droga e as auxiliamos a decidirem, por si mesmas, protegerem-se dos riscos do uso das drogas?

No mês de maio de 2001, a Folha de S. Paulo publicou um editorial (01/05) e uma notícia (04/05), nos quais se relata o caso de uma escola particular de classe média alta do Rio de Janeiro que expulsara quatro de seus alunos por terem usado droga (maconha). 0 editorial comenta o dilema que a escola pôs aos alunos: dizer a verdade e enfrentar um castigo como a expulsão ou mentir e escapar ao castigo? A escola expulsou os alunos que confessaram e não, obrigatoriamente, todos os que fumaram maconha. 0 jornal indaga aos leitores se a escola não acabou por ensinar a "lei de Gérson" na qual mentir para obter vantagens pessoais é mais vantajoso que dizer a verdade e sofrer as conseqüências. Na notícia do dia 4/05, o jornal relata que a escola, após a expulsão dos alunos, realizou uma grande assembléia com pais de alunos (segundo o jornal estavam presentes mais de 230 pessoas) para que fosse discutido o que fazer em caso de uso de drogas pelos alunos. Ouviram-se as mais variadas opiniões e chegou-se a conclusão que estabelecer limites claros e exigir que sejam cumpridos são elementos fundamentais para a educação dos adolescentes A notícia finaliza dizendo que a escola promoveu o debate como uma forma de expressar as suas próprias dúvidas sobre o assunto. A diretora da escola disse que não iria rever a expulsão já realizada, mas que pretendia iniciar um processo permanente de diálogo com os pais e alunos por meio de grupos de discussão de vários temas.

Aproveito esses dois casos para mostrar diferentes atitudes que as escolas podem tomar para disciplinar ou educar moralmente seus alunos. Num, o controle se fez pela policia - uma autoridade externa à escola, noutro, pela direção. Num, a investigação humilhante se justifica para "salvar" os inocentes e iden- 
tificar os culpados; noutra, espera-se que os alunos confessem seus erros voluntariamente; numa, a diretora toma uma atitude isolada e que pode ser, ou não, apoiada pelos professores da escola após o fato transcorrido; noutra, também após uma decisão tomada pela direção, as dúvidas são retomadas numa grande assembléia...0ra, ainda que as duas escolas possam ter cometido erros e acertos, perguntamos qual delas mais se aproximou de uma educação para a autonomia?

É preciso considerar nesses exemplos que estamos falando de escolas que se distanciam entre si cada vez mais: as públicas e as particulares. Em pesquisa recente (Menin, 2000) vimos que as opiniões de alunos de escolas públicas e particulares sobre lei, justiça, crimes, etc., às vezes se opõem. Ao questionarmos 480 alunos sobre se seria certo uma diretora de escola chamar a polícia para controlar alunos que estavam "aprontando", constatamos que nas escolas particulares 51\% dos alunos achavam a atitude da diretora injusta e $27 \%$ justa (houve $20 \%$ de respostas do tipo "depende" ou que davam outras alternativas de ação), e nas escolas públicas, $60 \%$ dos jovens achavam que era justo chamar a polícia, $29 \%$ injusto ( $8 \%$ de outras respostas e $2 \%$ de "não sei") (Menin, 2001, p. 316). Questiono-me se essas respostas indicam que só nas escolas públicas acontecem "casos de polícia" ou se se está evidente que há uma mentalidade completamente diferente, nesses dois ambientes escolares, sobre como educar. Acredito mais na segunda alternativa e penso que devamos estar atentos para esses dois códigos morais que podem estar acontecendo nesses dois espaços sociais tão diversos que são as escolas públicas e as particulares.

Sou contra listas, guias ou receitas de como educar moralmente. Acredito que a educação moral se faz pela ação orientada por alguns princípios fundamentais, tais como a justiça, a dignidade, a solidariedade, iluminados pelo respeito mútuo entre as pessoas e que pode ter um alcance cada vez maior. Nessa educação moral não há lugar para certezas, mas as dúvidas podem ser sempre discutidas. E é essa discussão o método de educação moral.

\section{Referências bibliográficas}

BRASIL, Secretaria de Educação Fundamental.Parâmetros Curriculares Nacionaiş terceiro e quarto ciclo: apresentação dos temastransversais. Brasília: MEC/SEF, 1998.

BUXARRAIS, M.R; Martínez, M.; Puig J.; Trilla, J. M.Laeducaciónmoralenprimariayen secundaria.[s.I.] Ministerio de Educación yCiencia, 1990

BUXARRAIS, M. B.La formación del profesorado en educación en valores: propuesta y materiales Spain: Desclée de Brouwer, 1997.

CABANAS, J. M. Q. Educación moral y valores.Revista de Ciencias de la Educación,n. 166, abr-jun. 1996.

FARIA, A. C. Pais e estudantes da escola Parque divergem sobre a expulsão de alunos.Folha de S. Paulq São Paulo, 4.05.2001.

KLÉBIS,M. A.; MENIN, M. S. S. A disciplina e a educação em valores nas escola.Estudos,n. 10; dez. 2000.

KOHLBERGL.Psicologia del desarrollo mora/Bilbau: Biblioteca de Psicologia, Desclée de Brouwer, 1992.

LEPRE, R. M Aindisciplina na escola e os estágios de desenvolvimento moral na teoria de Jean Piaget Marília; 2001. Dissertação (Mestrado)-Unesp/Marília. 
MARTINEZ, M. M.El contrato moral do profesorado.condiciones para una nueva escuela. Bilbau: Desclée de Brouwer, 1998.

MARTINEZ, M. M.; PUIG, J. M.La educación moral: perspectivas de futuro y técnicas de trabajo.Barcelona: I.C.E./Ed. Graó de Serveis Pedagògics, 1994.

MENIN, M. S. S. A construção da democracia e a escola um estudo sobre representações políticas e interações verbais no $2^{\circ}$ grau. São Paulo; 1992. Tese (Doutorado) - Instituto de Psicologia da Universidade de São Paulo.

Representações sociais de lei, crime e injustiça em adolescentes.Presidente Prudente; 2000. Tese (Livre-Docência) Faculdade de Ciências e Tecnologia daUnesp.

MENTRAé uma droga, a: editorial.Folha de S. Paulo,São Paulo; 01.05.2001. p. 2.

PIAGET, J. Os procedimentos de educação moral. In: MACEDO, L. (Org.)Cinco estudos de educação moral.São Paulo: Casa do Psicólogo, 1996.

. Ojulgamento moral na criança.São Paulo: Mestre Jou, 1977.

PUIG, J. M.Ética e valores: métodos para um ensino transversal.São Paulo: Casa do Psicólogo, 1998.

SHIMIZUAM As representações sociais de moral de professoras cas quatro primeiras séries do ensino de $1^{\circ} \mathrm{grau}$.Marília; 1998. Dissertação (Mestrado)-Unesp.

Recebido em 07.01.2002

Aprovado em 27.03.2002

MariaSuzanaDeStefano Menin mestre e doutora em Psicologia Escolar no Instituto de Psicologia da USP e livre-docente em Psicologia da Educação e do Desenvolvimento pela UNESP, é professora de Psicologia da Educação e do Desenvolvimento da Faculdade de Ciências e Tecnologia e coordenadora do curso de pós-graduação em Educação -Formação de professores - da UNESP, emPresiderte Prudente. 